\title{
Correspondence
}

Journal of Medical Genetics, 1980, 17, 404-405

\section{Primary protrusio acetabuli in four generations of an Italian family}

SIR,

Protrusio acetabuli is a pelvic deformity characterised by an abnormally deep or intruded ace-

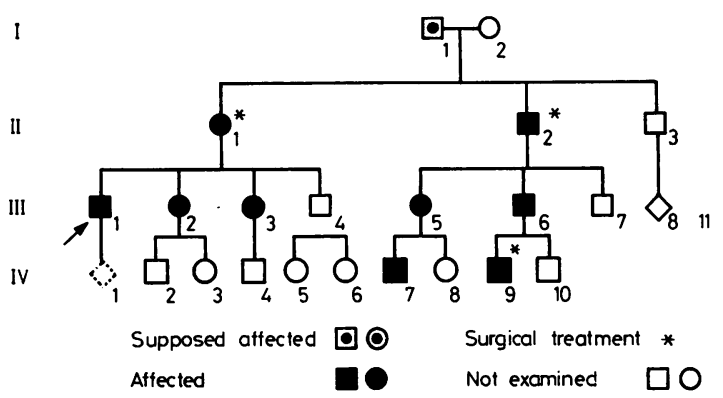

FIG 1 Family pedigree. tabulum. Two different types are generally recog- $\frac{\bar{D}}{\bar{D}}$ nised: a primary or idiopathic form, and a secondary $\underset{\complement}{\square}$ one resulting from well known recognised diseases. In the former condition, where an obvious cause is lack- ing, familial and racial influences on pathogenesis have been postulated. Genetic or environmental $\overrightarrow{\vec{\omega}}$ factors could be involved as well. Some cases suggest the possibility of heritability, though data about this have been very few so far. ${ }^{1-5}$

We have observed a family in which several $\vec{v}$ members in four generations were affected (fig 1). ir The deformity was present in both hips and caused $\vec{\phi}$ stiffness and limitation of abduction in all the $\circ$ patients. The symptoms started during the second or third decade and became severe in older persons $\vec{O}$ because of ankylosis and pain. No biochemical or metabolic abnormalities were found. Three of nine $\frac{0}{0}$ affected members required surgical treatment $\stackrel{\Phi}{-}$ (asterisks in fig 1) with satisfactory results. Physio- $\overrightarrow{0}$
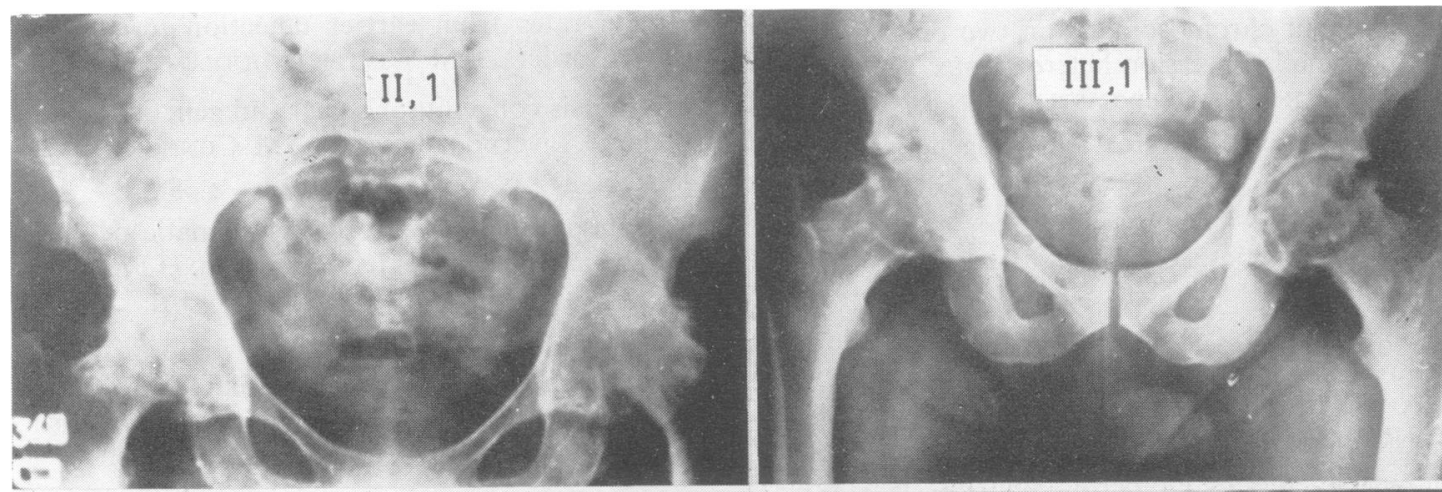

FIG 2 Radiographic features of some affected members of the family. Ages when $x$-rays were taken: 61 years (II.1 before treatment); 30 years (III.1); 27 years (III.2); 25 years (III.3). 


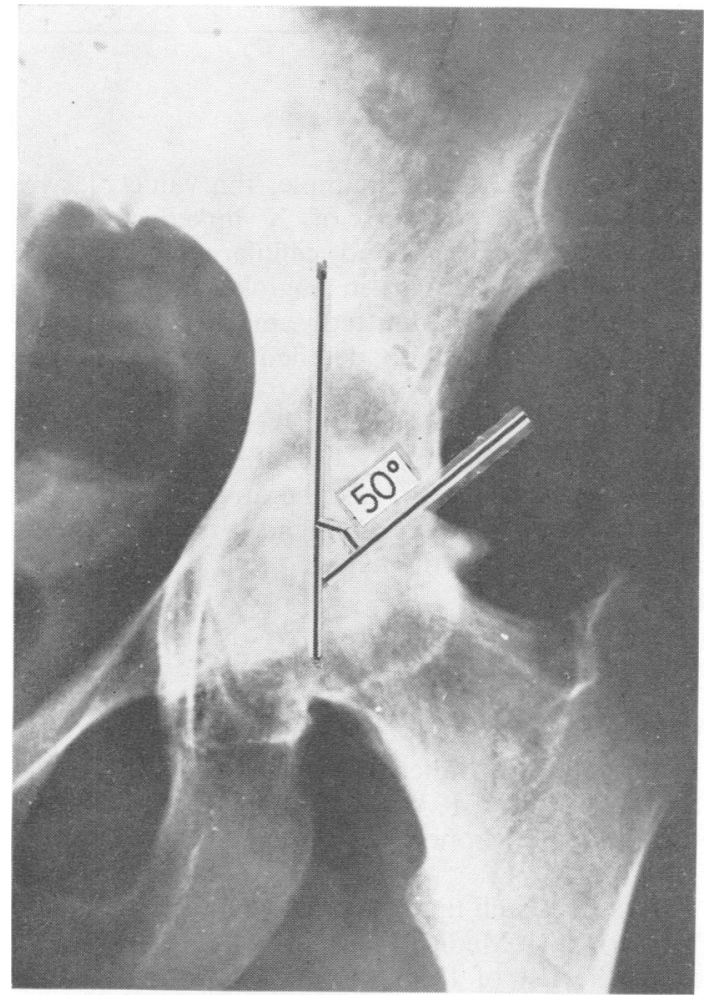

FIG 3 Angle of Wiberg: $50^{\circ}$ (obtained by the perpendicular through the mid-point of the femoral head and the upper and outer margin of the acetabulum).

therapy has been suggested for all the affected and they have been advised to avoid excessive physical stress. $X$-ray analysis showed radiological signs typical of the syndrome, including deep or protrusio acetabuli, peculiar 'tear drop'sign, and increased angle of Wiberg (about $50^{\circ}$, in contrast with a range between 20 and $35^{\circ}$ in normal subjects). It is noteworthy that in the same family deep and protrusio acetabuli have been observed as well (III.2) (fig 2). The two forms could be different expressions of a single gene, as also suggested by the affected family reported by MacDonald. ${ }^{5}$

The inheritance pattern in our cases is in accordance with an autosomal dominant gene with complete penetrance.

V Ventruto, M Stabile, M l Cavaliere, L Pagano, G Fioretti, and A Celona Centro per $i$ Disordini Genetici ed Ereditari del Metabolismo, Ospedale Cardarelli, Naples, Italy

\section{References}

1 Rechtman AM. Etiology of deep acetabulum and intrapelvic protrusion. Arch Surg 1936;33:122.

2 Brentrup H. Zur Frage der Protrusio Acetabuli. Arch Orthop Unfallchir 1942;42:241.

${ }^{3}$ Francis HH. The etiology, development and the effect upon pregnancy of protrusio acetabuli (Otto pelvis). Surg Gynecol Obstet 1959;109:295.

4 Hooper JC, Wyn Jones E. Primary protrusion of the acetabulum. J Bone Joint Surg(Br) 1971;53:23.

5 MacDonald D. Primary protrusio acetabuli. Report of an affected family. J Bone Joint Surg(Br) $1971 ; 53: 30$.

\section{The Gordon syndrome}

SIR,

In a recent report by Halal and Fraser in the Journal $(1979 ; 16: 149-50)$ the second family with the Gordon syndrome was recorded. We have recently evaluated a 5-year-old boy with findings consistent with this syndrome. In addition to cleft palate, camptodactyly of the 4th and 5th fingers bilaterally, and club foot, he had short stature, short lingual frenulum, small mouth, short neck, and mild kyphoscoliosis. Both testes were in the scrotum. He had a severe articulation disorder and hypernasal speech. A cineradiographic study of the oral and pharyngeal structures indicated that velar length and function was adequate for normal speech. Although the lingual frenulum was short, all articulatory contacts could be achieved. No hearing loss was present. Routine laboratory investigations and chromosome analysis were normal. Dermatoglyphic studies showed no unusual findings except that he had three unusually large whorl patterns on the fingertips with extralimital triradii. Hand pattern profile analysis, which was difficult to carry out because of camptodactyly, was interpreted as normal. An intravenous pyelogram was normal. However, fusion of the posterior elements of the lumbosacral junction of $\mathrm{L} 5$ to $\mathrm{S} 1$ on the right was noted.

The mother, of American Indian ancestry, was 23 years of age at the time of the patient's birth and the father 29. The pregnancy was at term and uncomplicated. A claim that the mother was an alcohol and drug abuser was made but could not be substantiated. There was no one on the maternal side with similar birth defects, but a paternal cousin had a cleft lip and another cousin was reported to have a club foot. Neither of these patients was available for study.

\section{Burhan Say, David H Barber, ROBERT C THOMPSON, AND LAWRENCE G LEICHTMAN Children's Medical Center, PO Box 35648 .} Tulsa, Oklahoma 74135, USA 